\title{
A CONSTRUÇÃO JURÍDICA DA INTERAÇÃO SEXUAL: HIERARQUIA VALORATIVA E PUNITIVA NA LEGISLAÇAO PENAL PORTUGUESA
}

Maria João Faustino ${ }^{1}$

Resumo: O presente artigo propõe uma análise sociojurídica dos atos sexuais com relevância penal, consagrados na legislação penal em curso no contexto jurídico português. A partir do mapeamento da legislação em vigor e do enquadramento doutrinário que lhe concerne, procedeu-se à identificação das categorias, conceitos e representações fundamentais da criminalidade sexual, procurando a deteção do fundo normativo concernente à interação sexual juridicamente consagrada. Procedendo à inquirição e análise crítica de tais categorias e distinções fundamentais, defendo que a criminalidade sexual aponta para uma conceção fisicalista, gradativa e piramidal do corpo sexualizado e da agressão sexual. $\mathrm{O}$ escalonamento valorativo é erguido pela hierarquização dos atos criminalmente previstos: contactos de natureza sexual; atos sexuais de relevo e atos sexuais de especial relevo. A construção piramidal da sexualidade tem como paradigma e expoente referencial a penetração vaginal, correspondendo ao conceito de 'imperativo coital'.

Palavras-chave: legislação penal portuguesa; criminalidade sexual; ato sexual de relevo; violação; cópula

\begin{abstract}
This study presents a sociological and legal analysis of the criminally relevant sexual acts in the context of the Portuguese legal system. Starting from the mapping of the current legislation and its related doctrinal production, the key categories, concepts and representations of sexual criminality were identified. It is argued that a physicalist, gradational and pyramidal conception of sexed bodies and sexual aggression underpins the current
\end{abstract}

\footnotetext{
${ }^{1}$ Licenciatura em Filosofia; Mestrado em Jornalismo; Bolseira Doutoramento FCT (área de investigação: sexualidade e tecnologia)
} 
Portuguese criminal law. The scale of criminal sexual relevance is constructed in hierarchical categories: contacts of sexual nature, relevant sexual acts and especially relevant sexual acts. The paradigmatic and higher standard of this pyramidal construction is the penetration of a vagina by a penis, which corresponds to the concept of 'coital imperative'

Keywords: Portuguese criminal law; sex crimes; relevant sexual act; rape; coitus

\section{INTRODUÇÃO}

\section{Contexto normativo e evolução} legislativa

$$
\text { A arquitetura }
$$

jurídica da criminalidade sexual, abrigada pelo capítulo V do Código Penal Português - Dos crimes contra a liberdade e autodeterminação sexual -, tem no seu ethos a salvaguarda da liberdade sexual, bem jurídico pessoal. $\mathrm{O}$ seu horizonte justificativo não é, portanto, a defesa de uma moral sexual dominante, ou a vocação prescritiva de uma ética sexual (e decorrente estigmatização de comportamentos sexuais que se lhe afigurassem desviantes). Se esse foi, contudo, o fundo normativo do direito penal sexual português, a viragem programática concretizada na revisão do Código Penal de 1995 afigura-se assaz importante: os crimes sexuais deixaram então "de ser crimes contra os fundamentos ético-sociais da vida social, como sucedia com os artigos $201^{\circ}$ a $218^{\circ}$ do CP de 1982, para passarem a ser crimes contra a liberdade e autodeterminação sexual da vítima" (Albuquerque, 2015: 639). Sendo que "é a liberdade sexual de um indivíduo que está em causa e que é tutelada e não a liberdade sexual de uma comunidade" (Lopes, 2008: 26), surge como corolário do novo enquadramento legal a não incriminação de "qualquer espécie de actividade sexual praticada por pessoas adultas, em privado e com consentimento" (Gonçalves, 2007: 621). É sobre este tecido normativo que serão enquadradas e balizadas as ulteriores revisões do Código Penal.

Diferentemente do que hoje se verifica, a visão tradicional da violação consistia na “cópula não conjugal forçada numa mulher honesta (...), a conjunção carnal obtida por um homem de uma mulher fora das regras de 
acesso normal à obtenção dessa 'mercadoria'.12”, escreve Teresa Pizarro Beleza (1994: 53). Longe do paradigma da tutela da liberdade sexual individual hoje consagrada, "eram as regras de obtenção lícita do acesso ao comércio carnal com uma mulher honesta, senão mesmo virgem - através do casamento, com o consentimento paterno - que estavam fundamentalmente em causa na imagem tradicional da violação" (1994: 53). Ora, "no desenho e na compreensão político-criminal tradicionais desta figura típica começava por desempenhar papel fundamental a circunstância da cópula com mulher - e não de qualquer outro acto sexual - poder resultar a gravidez", sendo esta potencial repercussão aliada à proteção das "representações epocais comuns da moralidade sexual", onde

a cópula forçada representaria para a mulher (nomeadamente para a mulher virgem, ou a mulher casada

2 Beleza refere, neste contexto, a previsão no Código Penal de 1886 da "exclusão do casamento (art. $393^{\circ}$ ), a punição equivalente ou quase equivalente do estupro (art. $392^{\circ}$ ), a obrigação de dote e o casamento-remédio (art. 400) " para efeitos de violação (1994: 53).

3 Refira-se, neste contexto, a crítica de Teresa Pizarro Beleza, datada de 1990. Considerando a exclusão que o coito oral ou anal forçados, assim como "a violação com objectos inanimados", recebiam no então Código Penal vigente, Beleza quando praticada por alguém que não o marido) um ataque particularmente e incomparavelmente grave ao seu pudor e à sua honradez tanto do ponto de vista individual, como social (Figueiredo Dias, 2012: 743).

Desta visão de partida até ao atual quadro criminal verificou-se um longo percurso cujo sentido tendencial tem sido o do alargamento - e "consequente descaracterização", na compreensão de Figueiredo Dias, da "figura típica tradicional” (2012: 744). Vejamos, sumariamente, algumas das alterações substantivas que, desde 1995, ilustram tal asserção. É neste ano que se equipara o coito anal à cópula, para efeitos de moldura penal $2^{3}$. A extensão do conceito de violação avoluma-se, em 1998, pela inclusão do coito oral, sendo que ainda se considera que o "núcleo da conduta típica do crime de violação (cópula, coito anal ou coito oral) exige sempre a penetração do

argumentava que "tais actos podem ser tão ou mais traumatizantes e humilhantes para a mulher, quando executados contra a sua vontade, do que a cópula dita normal". Concluía, assim, que "a sua exclusão do âmbito da violação reforça a definição de esta não como crime contra a liberdade e a integridade da mulher, o que ela é em realidade e a lei deveria reconhecer, mas como um crime contra essa estranha entidade a que o Código chama 'fundamentos ético-sociais' e o projecto chamava 'costumes', provavelmente querendo dizer 'bons" (1990: 221-222). 
órgão sexual masculino numa das cavidades (vagina, ânus ou boca) indicadas" (Silva Dias, 2000: 59). Este alargamento seguiu, afirma Maia Gonçalves,

a orientação consagrada no Código Penal francês de 1994, e por se entender que estas formas de penetração sexual constituem, de acordo com os estudos da psicologia e da psiquiatria, violações da liberdade sexual da vítima identicamente intensas e estigmatizantes (2007: 621).

Também nesta data se verifica a neutralização do género, abandonando-se a especificação da mulher como único sujeito-vítima da violação; em paralelo, passou a figurar na moldura criminal $o$ assédio sexual - "uma forma de coação sexual fundada no abuso de autoridade resultante de uma relação de dependência hierárquica, económica ou de trabalho" (Albuquerque, 2015: 640). Volvida quase uma década, a reforma de 2007 concretiza mais um capítulo no alargamento do conceito de violação, abarcando agora também a introdução vaginal ou anal de partes do corpo ou objetos, sendo que “esta concepção de violação é estendida a todos os artigos que antes referiam a cópula" (Ventura, 2013: 352). Assim, a reforma do CP de 2007 diminuiu de novo o âmbito do conceito de ato sexual de relevo, equiparando a penetração vaginal e anal com objetos ou partes do corpo à cópula e, desse modo, subtraindo os atos de penetração com objetos ou partes do corpo ao regime (menos grave) da coação sexual e submetendo-os ao regime (mais grave) da violação (Albuquerque, 2015: 641).

A ratificação por Portugal em 21 de Janeiro de 2013, e posterior entrada em vigor a 1 de Agosto de 2014, da Convenção do Conselho da Europa para a Prevenção e o Combate à Violência contra as Mulheres e a Violência Doméstica, designada Convenção de Istambul, impôs subsequentes alterações à ordem jurídica penal. No espírito de "avanço ideológico e simbólico na teorização da violência contra as mulheres" (Sottomayor, 2015, 106) que a Convenção representa, concebendo "a violência contra as mulheres como violência de género, de carácter estrutural e epidémico" (idem), as mudanças na legislação penal de 2015 apresentam, para além de novas incriminações (como a perseguição e o casamento forçado), alterações nas disposições referentes à coação sexual (art. $\left.163^{\circ} \mathrm{CP}\right)$, violação (art. $\left.164^{\circ} \mathrm{CP}\right)$ e importunação sexual (art. 170 $\mathrm{CP})$. 


\author{
Considerando o objeto deste \\ estudo e o problema que o encabeça, a \\ análise subsequente privilegiará os três
}

enunciados legais, cuja formulação atual se reproduz:

Artigo

$163 .^{\circ} \cdot 3^{4}$

\title{
Coacção sexual
}

1 - Quem, por meio de violência, ameaça grave, ou depois de, para esse fim, a ter tornado inconsciente ou posto na impossibilidade de resistir, constranger outra pessoa a sofrer ou a praticar, consigo ou com outrem, acto sexual de relevo é punido com pena de prisão de um a oito anos. 2 - Quem, por meio não compreendido no número anterior, constranger outra pessoa a sofrer ou a praticar ato sexual de relevo, consigo ou com outrem, é punido com pena de prisão até 5 anos.

\author{
Artigo 164..$^{\circ}$ \\ Violação $(4)^{5}$
}

4 Antes da última reforma na sequência da ratificação e aplicação do disposto na Convenção de Istambul, o texto em vigor (datado de 2007) dispunha:

\section{Artigo}

$1633^{\circ}$

\section{Coacção sexual}

1 - Quem, por meio de violência, ameaça grave, ou depois de, para esse fim, a ter tornado inconsciente ou posto na impossibilidade de resistir, constranger outra pessoa a sofrer ou a praticar, consigo ou com outrem, acto sexual de relevo é punido com pena de prisão de um a oito anos.

2 - Quem, por meio não compreendido no número anterior e abusando de autoridade resultante de uma relação familiar, de tutela ou curatela, ou de dependência hierárquica, económica ou de trabalho, ou aproveitando-se de temor que causou, constranger outra pessoa a sofrer ou a praticar acto sexual de relevo, consigo ou com outrem, é punido com pena de prisão até dois anos.

5 Antes desta última reforma na sequência da ratificação e aplicação do disposto na Convenção de Istambul, o texto em vigor (datado de 2007) dispunha:

\section{Artigo 164.}

\section{Violação}

1 - Quem, por meio de violência, ameaça grave, ou depois de, para esse fim, a ter tornado inconsciente ou posto na impossibilidade de resistir, constranger outra pessoa: a) A sofrer ou a praticar, consigo ou com outrem, cópula, coito anal ou coito oral; ou b) A sofrer introdução vaginal ou anal de partes do corpo ou objectos; é punido com pena de prisão de três a dez anos. 2 - Quem, por meio não compreendido no número anterior e abusando de autoridade resultante de uma relação familiar, de tutela ou curatela, ou de dependência hierárquica, económica ou de trabalho, ou aproveitando-se de temor que causou, constranger outra pessoa: a) A sofrer ou a praticar, consigo ou com outrem, cópula, coito anal ou coito oral; ou b) A sofrer introdução vaginal ou anal de partes do corpo ou objectos; é punido com pena de prisão até três anos. 
1 - Quem, por meio de violência, ameaça grave, ou depois de, para esse fim, a ter tornado inconsciente ou posto na impossibilidade de resistir, constranger outra pessoa: a) A sofrer ou a praticar, consigo ou com outrem, cópula, coito anal ou coito oral; ou b) A sofrer introdução vaginal ou anal de partes do corpo ou objetos; é punido com pena de prisão de três a dez anos.

2 - Quem, por meio não compreendido no número anterior, constranger outra pessoa: a) A sofrer ou a praticar, consigo ou com outrem, cópula, coito anal ou coito oral; ou b) A sofrer introdução vaginal ou anal de partes do corpo ou objetos; é punido com pena de prisão de 1 a 6 anos.

Artigo

Importunação sexual.5

Quem importunar outra pessoa, praticando perante ela atos de carácter exibicionista, formulando propostas de teor sexual ou constrangendo-a a contacto de natureza sexual, é punido com pena de prisão até 1 ano ou com pena de multa até 120 dias, se pena mais grave lhe não couber por força de outra disposição legal.

ANÁLISE

Gradação valorativa, gradação punitiva: os atos sexuais com relevância penal

Ora, provindo da revisão de 2007, resulta um quadro criminal que diferencia "três categorias de actos sexuais com relevância penal: a cópula, o coito anal, o coito oral e a introdução vaginal ou anal de partes do corpo ou objectos; os demais actos sexuais de relevo; e os meros contactos de natureza sexual" (Rodrigues e Fidalgo, 2012: 828). No mesmo sentido, e referindo como legado provindo da mesma revisão da legislação penal, Paulo Pinto de Albuquerque identifica a distinção entre

atos sexuais de especial relevo [...] (cópula, coito anal e oral e penetração vaginal e anal com objetos ou partes do corpo), atos sexuais de relevo (atos sexuais com gravidade objetiva), atos de contacto sexual (atos sexuais sem gravidade objetiva) e atos de exibicionismo (Albuquerque, 2015: 641 , realces originais).

\footnotetext{
${ }^{6}$ Antes desta última reforma na sequência da ratificação e aplicação do disposto na Convenção de Istambul, o texto em vigor (datado de 2007) dispunha:

Artigo

$170 .{ }^{\circ}$

Importunação sexual

Quem importunar outra pessoa praticando perante ela actos de carácter exibicionista ou constrangendo-a a contacto de natureza sexual é punido com pena de prisão até um ano ou com pena de multa até 120 dias, se pena mais grave lhe não couber por força de outra disposição legal.
} 
A identificação das referidas categorias sugere já um escalonamento valorativo, uma apreciação gradativa, implícita na hierarquia do relevo dos atos e na enunciação piramidal: as referências à cópula e ao coito, anal e oral distinguemse à partida dos demais conceitos, cujo referente não encontra o mesmo grau de precisão.

\section{A base da pirâmide valorativa}

$\mathrm{Na}$ visitação e problematização das categorias elencadas, cumpriremos o percurso inverso ao da sua exposição, começando com aquela que se intui menos gravosa - sobretudo pela formulação supra citada que a introduz como "meros actos de contacto sexual" (Rodrigues e Fidalgo, 2012: 828). A disposição legal do artigo $170^{\circ} \mathrm{CP}$, epigrafado "Importunação sexual", prevê, refere Paulo Pinto de Albuquerque, "dois crimes distintos: o crime de ato de carácter exibicionista e o crime de contacto de natureza sexual" (2015: 675) - sendo que ambos visam a tutela da liberdade sexual de outra pessoa, ainda que este bem jurídico seja "protegido de modo diverso por cada uma das incriminações" (2015: 675). No mesmo sentido, Anabela Miranda Rodrigues e Sónia Fidalgo afirmam que “o legislador configurou no mesmo artigo (...) dois comportamentos cuja ilicitude típica é diferente" - especificamente, "a importunação de outra pessoa através da prática, perante ela, de actos de carácter exibicionista, e a importunação de outra pessoa por meio de constrangimento a contacto de natureza sexual" (2012: 816).

$\mathrm{O}$ ato exibicionista consiste, afirma Pinto de Albuquerque, "numa ação com conotação sexual realizada diante da vítima, que suscite o receio fundado da prática subsequente de um ato sexual com a vítima" (2015: 676, realce no original). Diferentemente, o contacto de natureza sexual é descrito como "ação com conotação sexual realizada na vítima, que não tem a gravidade do ato sexual de relevo" (2015: 677, realce no original). Como exemplos possíveis do primeiro tipo de incriminação, o autor invoca "o desnudamento do agente perante a vítima", "o desnudamento em lugar público ou mesmo de acesso restrito", ou 
ainda "a realização de ato sexual com terceiro diante da vítima" (2015: 676).

Traço determinante do ato exibicionista "é que ele ocorra perante a vítima, isto é, independentemente de o corpo da vítima ser tocado" (Rodrigues e Fidalgo, 2012: 817, realce original): aqui se jogará, portanto, a fronteira entre ato exibicionista e contacto de natureza sexual. Anabela Miranda Rodrigues e Sónia Fidalgo sublinham que, dado o enquadramento legal mais lato dos atos exibicionistas e a sua destinação protetiva da liberdade sexual, a justificação da criminalização se apreende

apenas e só na exacta medida em que $\mathrm{o}$ dito acto exibicionista representa, para a pessoa perante o qual é praticado, um perigo de que se lhe siga a prática de um acto sexual que ofenda a sua liberdade de autodeterminação sexual por forma a constituir crime (Rodrigues e Fidalgo, 2012: 818) (realces originais).

Só assim será líquido, asseguram, que "é a liberdade sexual da pessoa visada com o acto exibicionista, já quando esta liberdade está em perigo, que a incriminação visa proteger" (2012: 818).

A exigência do toque para a verificação do contacto de natureza sexual é sublinhada elas autoras: este "traduz-se na prática no corpo da vítima - o agente tem de tocar o corpo da vítima - de um acto de natureza sexual", inferindo-se a exclusão de incriminação de "quaisquer actos sexuais que não impliquem o contacto físico entre o agente e a vítima e, por outro lado, quaisquer contactos físicos que não assumam natureza sexual" (2012: 828 , realce no original).

O contacto de natureza sexual pode incluir, defende Pinto de Albuquerque, "o toque (com objetos ou partes do corpo) da nuca, do pescoço, dos ombros, dos braços, das mãos, do ventre, das costas, das pernas e dos pés da vítima" (2015: 677). São admitidos ainda, para efeitos de preenchimento do conceito de contacto de natureza sexual, "a aproximação física do corpo do agente ao da vítima de modo que quase se toquem" (2015: 677), sendo que esta aproximação é diferentemente valorada: inclui "a aproximação frente a frente e da frente do agente às costas da vítima", mas exclui "a aproximação das costas do agente às costas da vítima" (2015: 677). Em todo o caso, estas manifestações não carregam, defende a doutrina citada, a dimensão lesiva dos atos sexuais de relevo; a sua 
criminalização resulta da "perspectiva do legislador de 2007", para o qual "qualquer constrangimento a contacto de natureza sexual pode constituir uma ofensa com significado sexual que merece (ainda) tutela penal". $6^{7}$ (Rodrigues e Fidalgo, 2012: 828).

Atos sexuais de relevo

A categoria de atos sexuais de relevo afigura-se, na expressão de Pinto de Albuquerque, como "peça central" do "novo enquadramento" legado da revisão do Código Penal de 1995 (2015: 640). Coerente com o espírito da juridicidade alavancado por tal revisão, o conceito de ato sexual de relevo "não tutela a moral sexual ('os sentimentos gerais da moralidade sexual', mencionados no artigo $205 .^{\circ}$, n. ${ }^{\circ} 3$, do $\mathrm{CP}$ de 1982$)$ da sociedade, de um grupo particular da sociedade ou da vítima" (2015: 640). Assim, defende o autor, o conceito

\footnotetext{
7 Testemunho de uma certa tendência de neocriminalização, que terá concorrido com a descriminalização de condutas anteriormente sancionadas, como a homossexualidade e o adultério: "as alterações de 1995 e as posteriores alargaram o âmbito da incriminação de crimes já previstos em épocas anteriores, como a violação, e
}

indeterminado de ato sexual de relevo encontra na "perspetiva normativa objetiva própria de uma sociedade democrática, pluralista e tolerante" (2015: 640; realce original) o critério de determinação do seu conteúdo.

$\mathrm{O}$ ato sexual de relevo resulta, nesta perspetiva, como "a ação de conotação sexual de uma certa gravidade objetiva realizada na vítima" (Albuquerque, 2015: 645). Daqui se depreende um duplo requisito: a feição sexual da ação e a gravidade considerada merecedora de tutela penal. No mesmo sentido escreve Figueiredo Dias, afirmando que o ato sexual de relevo deve possuir uma "natureza, um conteúdo ou um significado directamente relacionados com a esfera da sexualidade e, por aqui, com a liberdade de determinação sexual de quem o sofre ou pratica", aferíveis "de um ponto de vista predominantemente objectivo e segundo uma compreensão natural (2012: 718-719, realces originais).

criminalizaram comportamentos que estavam total ou parcialmente fora do domínio da relevância penal, como o abuso sexual de crianças e de menores dependentes (art. ${ }^{\circ} 171 .^{\circ}$ e $172^{\circ}$ ), a importunação sexual $\left(\right.$ art. $^{\circ} 170^{\circ}$ ), pornografia de menores $\left(\right.$ art. $\left.^{\circ} 176 .^{\circ}\right)$ e o recurso à prostituição de menores (art. ${ }^{\circ} 174^{\circ}$ )" (Sottomayor, 2011: 285-286). 
A doutrina aponta para um espectro de possibilidades quanto à verificação do conceito de ato sexual de relevo. Entre elas, contam-se "a cópula vulvar e o toque, com objetos ou partes do corpo, nos órgãos genitais, seios, nádegas, coxas e boca" (Albuquerque, 2015: 646; realces originais); “ejacular ou urinar sobre a vítima” (Gonçalves, 2007: 624); o "beijo lingual”, a "excitação do clitóris de uma paciente na ocasião de um exame ginecológico", assim como "passar as mãos nas coxas, seios, órgãos sexuais", ou ainda "todas as formas de manipulação (v.g. masturbação), com ou sem ejaculação, no caso da masturbação de um pénis (Lopes, 2008: 29).

Para efeitos de verificação legal da coação sexual, plasmada no art. ${ }^{\circ}$. $163^{\circ}$ $\mathrm{CP}$, o ato sexual de relevo deve resultar de constrangimento da vítima, mediante violência, ameaça grave, ou de ação destinada a colocar a vítima inconsciente ou na impossibilidade de reagir, ou ainda, desde a última reforma legal, por qualquer outro meio não compreendido no enunciado do número 1 do art. $^{\circ} 163 .^{\circ}$. Daqui resulta que "a conduta típica" se traduz, nas palavras de Figueiredo Dias, em ato de coação "imediatamente dirigido à prática, activa ou passiva, de um acto sexual de relevo" (2012: 724; realce original). Depreende-se que tanto a conduta ativa como a passiva - obrigação de sofrer ou praticar - preenchem o tipo objetivo do crime: a "coacção típica ao acto sexual pode ter lugar (...) num duplo enquadramento fáctico relativamente à vítima: ou levando-a a sofrê-lo no seu corpo; ou levando-a a praticá-lo com o autor ou com terceiro" (Dias, 2012: 724; realces e itálico no original).

Tal não implica, contudo, a mutualidade do contacto corporal, como ressalta Figueiredo Dias: "o aludido toque no corpo da vítima não tem de ser levado a cabo pelo corpo do agente ou de terceiro: não é indispensável o mútuo contacto corporal", resultando assim que "toques com objectos ou mesmo acções como as de ejacular sobre a vítima" integram já o conceito de acto sexual de relevo para efeitos do artigo $163 .^{\circ} \mathrm{CP}$ (2012: 723; realce no original).

Em concordância, escreve Maia Gonçalves que "não é indispensável o contacto mútuo com o corpo da vítima", admitindo que os atos de introdução de 
objetos e as supra referidas ações de ejacular ou urinar sobre a vítima como passíveis de constituírem atos sexuais de relevo (2007: 624).

Expoente piramidal: a especial relevância na tipificação dos crimes sexuais

Vejamos, agora, os pressupostos da tipificação dos "atos sexuais de especial relevo", na expressão de Pinto de Albuquerque - a saber, "cópula, coito anal, coito oral e penetração vaginal ou anal de partes do corpo ou objetos". Contudo, tal diferenciação e autonomização categorial não deve, defende Figueiredo Dias, conduzir-nos à absoluta demarcação entre ato sexual de relevo e os referidos atos sexuais de especial relevo, subsumíveis na previsão legal da violação - art. $^{\circ} 164 .^{\circ} \mathrm{CP}$. Tal exercício seria erróneo, escreve o autor, porquanto "a violação "é apenas uma especialização da coacção sexual do artigo $1633^{\circ}-1$, constituindo esta, por isso, o tipo fundamental, digamos, a lex generalis" (2012: 716; realces e itálico no original). Daqui resulta que:

não seria correcto - nem sistemática, nem teologicamente - "opor" ou "cindir" os tipos de coacção sexual e de violação, como se o cerne do primeiro residisse no "acto sexual de relevo" e o do segundo em coisa diferente, a saber, a "cópula", o "coito" ou a "penetração" (2012: 716).

Precisando, "a violação constitui apenas uma coacção sexual especial" (2012: 717; realce no original). No mesmo sentido, Maia Gonçalves escreve que "sendo a coacção sexual o tipo fundamental de crime, a violação não deixa de ser também uma coacção sexual, precisamente uma coacção sexual especial e qualificada" - do que se infere que "tanto a cópula como o coito anal e o oral são actos sexuais de relevo, precisamente os mais graves" (2007: 624).

Os atos sexuais de especial relevo encontram, ao contrário do conceito indeterminado de ato sexual de relevo, referentes determinados na previsão legal: a cópula, o coito anal e o coito oral, e a introdução vaginal ou anal de partes do corpo ou objetos. Tal pluralidade enunciativa resulta de um trajeto legislativo que tem imposto progressivas mutações ao figurino tradicional da violação, primordialmente consagrada como cópula coagida sobre uma mulher. 
A determinação jurídica de cópula encontra larga convergência na doutrina como penetração vaginal pelo pénis. Neste sentido, Pinto de Albuquerque refere-se-lhe como "ato pelo qual o pénis de um homem é introduzido na vagina de uma mulher, haja ou não emissio seminis" (2015: 655). José Mouraz Lopes define-a como "resultado de uma relação heterossexual de conjunção carnal entre órgãos sexuais masculinos e femininos" (2016: 60), sendo que "a introdução completa ou incompleta do órgão sexual masculino na vagina" (2016: 61) se apresenta como requisito inultrapassável. De tal postulado resulta a exclusão, para efeitos de preenchimento do tipo objetivo do crime de violação (passíveis, portanto, de preenchimento do crime de coação sexual), a “cópula vestibular ou vulvar" - esta última consubstanciada "no contacto externo dos órgãos sexuais masculinos e femininos" consumado pela emissio seminis, "sem que se tenha verificado penetração do pénis na

\footnotetext{
${ }^{8}$ Poder-se-ia problematizar este reenvio para "o conceito médico-fisiológico", não apenas no sentido em que ele parece sugerir a abertura à receção jurídica da medicalização da sexualidade (Tiefer, 1995), mas também no sentido mais lato
}

vagina" (2016: 41). O mesmo é válido, acrescenta o autor,

quando as partes do corpo (v.g. dedos, língua) ou objetos (v.g. vibradores, paus) apenas contatam com a vagina ou ânus, mas inexiste introdução total ou parcial. Estamos perante um ato sexual de relevo que, no entanto, não integra o crime de violação, por não se subsumir no elemento típico "introdução" (Lopes, 2016: 41).

Em concordância, Jorge de Figueiredo Dias afirma como único sentido possível de cópula a "penetração da vagina pelo pénis" (2012: 749; realce no original); já Maia Gonçalves argumenta, contrariando posição previamente assumida no sentido do conceito ético-social de cópula, que "há bons argumentos no sentido de que a definição de cópula deve ser agora aferida pelo conceito médico-fisiológico. $7^{8} \mathrm{de}$ penetração do membro viril na vagina da mulher, embora só parcialmente" (2007: 630).

O conceito de cópula dispensa a emissio seminis para a sua verificação, conforme fixação jurisprudencial do

das relações entre Direito e Medicina (e seus condicionamentos recíprocos). Já na sua dissertação de Doutoramento, Teresa Beleza referia-se ao processo de naturalização pelo discurso médico na construção jurídica (1990). 
Supremo Tribunal de Justiça (STJ) (Acórdão n. ${ }^{\circ}$ 5/2003): "pese embora alguma hesitação da jurisprudência, temos como mais fundamentada a teoria de que no conceito de cópula se não exige a dita [emissio seminis]", pode ler-se no texto do acórdão. Justificando tal dispensa, o STJ considerou que "exigir-se na violação consumada o orgasmo ou ejaculação, como por vezes se lê, é um puro preciosismo, atendendo à essência do bem jurídico protegido", pelo que "a norma incriminadora contenta-se com a introdução do pénis na vagina, total ou parcial”. Tal estabilização do conceito impediria, conclui o acórdão, a subtração à previsão criminal dos agentes "incapazes de orgasmo, os que se dedicassem à prática do chamado coitus interruptus e até os que utilizassem preservativos, sem que se descortine uma razão válida de política criminal para sustentar tal distinção". A mesma fonte jurisprudencial fornece ainda indicações relevantes quanto à consideração da cópula: referindo-se ao coito vulvar ou vestibular, caracteriza estas manifestações como "as que mais se assemelham às relações sexuais completas", considerando não existir "nada mais aparentado com a natural união heterossexual".

Também no acolhimento jurisprudencial parece verificar-se a adesão à diferenciação apreciativa dos atos sexuais enunciados na violação. Apesar da equiparação legal para efeitos de crime e moldura penal, a perceção de quem aplica parece apontar para uma não horizontalização entre cópula, coito oral e anal, e penetração com partes do corpo ou objetos. Assim sugere Isabel Ventura, cujo levantamento das representações das/os magistradas/os, através de entrevistas em profundidade, aponta para:

[uma] notória [...] hierarquia
jurídica dos atos sexuais, encabeçada
pela CHV [cópula heterossexual
vaginal]. Não obstante uma
magistrada afirmar que, para muitas
mulheres, o sexo oral forçado é visto
como uma prática tão repugnante
quanto a CHV, os discursos dos/as
magistrados/s confirmam a
existência de uma hierarquia e a
adesão ao binómio normal/anormal
em matéria de práticas sexuais
(Ventura, 2016a: 631).

Descrevendo a "pirâmide hierárquica das práticas sexuais" detetável nos discursos dos agentes judiciais, Ventura refere que "a cópula oral é remetida para um lugar desvalorizado na pirâmide", ao passo que "a cópula anal 
surge como um contacto anormal" (2015: 632) apesar do tratamento igualitário que tal triangulação penetrativa recebe na letra da lei. A perceção hierarquizante de quem julga e aplica parece suportada por um entendimento da "CHV [cópula heterossexual vaginal] [...] como a relação sexual por excelência, colada a um cenário de [hétero]normalidade, contrariamente a outras práticas que emergem como atípicas" (Ventura, 2016a: 632).

Fisicalidade e copresença: a radicação somática, relacional e presencial dos atos sexuais

A tipificação piramidal dos atos sexuais com relevância penal exprime, como antecipámos, uma gradação valorativa: as categorias identificadas são estruturadas hierarquicamente; aos diferentes atos sexuais correspondem diferentes graus de ilicitude. Assim, escreve Inês Ferreira Leite que na codificação legal em causa

\footnotetext{
${ }^{9}$ Esta parece ainda surgir como ato paradigmático, ato-medida, da interação sexual no quadro criminal, apesar da mitigação imposta pela evolução legislativa analisada e sua equiparação à cópula, ao coito anal e coito oral, e introdução
}

temos uma distinção central entre um conjunto de actos especialmente lesivos da liberdade sexual (cópula ou coito e introdução de partes do corpo ou de objectos) e um conjunto de actos que, assumindo alguma gravidade ante a liberdade sexual, são menos lesivos da mesma (os actos sexuais de relevo) (2011: 69).

Ora, a construção gradativa dos atos e suas dimensões lesiva e punitiva deixa antever uma visão da sexualidade que encontra na fisicalidade e no confronto dos corpos a sua matriz. Esta fisicalidade, que se exprime em diferentes graus de efetivação, admite diversas matizes: o encontro potencial, nos atos exibicionistas; o contacto que dispensa a mutualidade, nos casos do contacto de natureza sexual e do ato sexual de relevo; e o toque que terá na reciprocidade o seu padrão, como é o caso dos atos sexuais de especial relevo.

$\mathrm{Da}$ prioridade punitiva da penetração no caso da cópula $(8)^{9}$, do coito anal ou oral, ou da introdução vaginal ou anal de partes do corpo ou objetos, parece resultar uma visão da penetração como último estádio, máximo expoente, do

vaginal ou anal com partes do corpo ou objetos. Refira-se, novamente, a fixação jurisprudencial do STJ, patente no acórdão n. ${ }^{\circ} 5 / 2003$, onde é aludida como "relações sexuais completas" e "natural união heterossexual". 
contacto: a intrusão nas cavidades do corpo é concebida como derradeiramente lesiva da liberdade sexual. Assim, Jorge de Figueiredo Dias e Pedro Caeiro pronunciam-se sobre "a relevância acrescida do contacto físico subjacente à cópula (e ao coito anal) " (1997: 1399), e Figueiredo Dias refere a "sua natureza, real ou assumidamente, especial" (2012: 716). Também Maia Gonçalves descreve a violação como "o mais grave dos crimes contra a liberdade sexual por ser o que mais intensamente lesa a liberdade e a autenticidade da expressão da vida sexual das pessoas" (2007: 629). É, neste sentido, reveladora a diferenciação doutrinária concernente à cópula - compreendida como introdução peniana, pelo menos parcial, da vagina -, e à cópula vulvar.

$\mathrm{O}$ ato (de violência) sexual é pressuposto e compreendido como ato físico de um agente sobre o corpo da vítima. Ainda que, como Pinto de Albuquerque, se afirme que "a ilicitude dos tipos já não se centra, como outrora, no ato físico do contacto sexual entre agente com a vítima, mas na violação da liberdade e da autodeterminação sexual da vítima" (2015: 640), graças à inclusão do constrangimento ao ato sexual com terceiro, descaracterizando os crimes sexuais como crimes de mão própria, deve admitir-se que a consumação do ato, apesar da autoria decisória e consequente imputabilidade, depende de um agente cujo corpo se confronta com o corpo da vítima. A fisicalidade é o contexto de fundo, e a copresença surge como condição necessária na criminalidade sexual.

Estamos, assim, perante a uma representação que postula, ou privilegia, o confronto de um corpo com outro corpo. Mesmo a dispensa da reciprocidade, salvaguardada nos contatos de natureza sexual e nos atos sexuais de relevo, não deve, contudo, obscurecer que estamos ainda perante um corpo que age sobre outro corpo: as ações de ejacular ou urinar sobre a vítima ou o uso de objetos implicam ainda que o corpo da vítima seja tocado ou objeto de manipulação por outrem, que sofra a ação física de um outro sujeito. $\mathrm{O}$ emprego de objetos também não desvirtua ou descaracteriza a realidade em questão: a exclusão da mutualidade do contacto não é exclusão do contacto físico entre agente e vítima - mesmo que este 
contacto seja mediado pela utilização de objetos.

Apontando a não punibilidade

como coação sexual. $9^{10}$ do "constrangimento a acto sexual de relevo praticado pelo agente ou por terceiro(s) perante a vítima" - sendo que é apenas punido " o constrangimento a acto praticado na vítima" - , Figueiredo Dias problematiza "o bom fundamento desta decisão legislativa”, considerando possível alegar-se que "quando está em causa a prática de acto sexual de relevo perante a vítima, é ainda de matéria atinente à esfera sexual que se trata e, por aí, de actuação lesiva, em último termo, da liberdade sexual da vítima” (2012: 722, realces originais). Porém, acrescenta: “contrapor-se-á, não é a autodeterminação sexual da vítima que directamente se põe em causa, mas verdadeiramente a sua liberdade pessoal de acção ou omissão" (2012: 722).

Contudo, e considerando que "a lei considerou ainda decisivo, na matéria, o tocar o corpo (eventualmente coberto

$10 \mathrm{O}$ autor admite, porém, a possibilidade da importunação sexual ou da coação, ao abrigo dos $\operatorname{artigos} 154^{\circ}$ ou $155^{\circ} \mathrm{CP}$, pela roupa) da vítima, reconhecendo aí um perigo intensificado para a sua autodeterminação sexual”, o autor sugere como possibilidade a deteção de uma “concepção em demasia fisiológico externa da sexualidade ('noli me tangere'.10 ${ }^{11}$ )" (realces originais, 2012: 722).

Exemplo de que a intromissão abusiva na esfera da sexualidade prescinde do contacto - ainda que este abuso nem sempre encontre previsão criminal -, Figueiredo Dias aponta a lacuna de punibilidade resultante do constrangimento à prática de ato da vítima sobre si própria:

Importa por outro lado considerar
que também não cabe na área de
tutela típica o caso em que o acto
sexual de relevo a que a vítima seja
constrangida se traduza em acto
sexual por ela praticado em si
própria (v.g., obrigar a vítima a
masturbar-se). Com efeito, a
exigência de que o acto seja
praticado consigo [ou com outrem]
não parece abranger o caso, antes
significa que o acto deve ser
praticado com o agente [ou com
outra pessoa]. Tudo o que nos resta
aqui é a punição, se disso for caso,
pelo crime de coacção dos arts. 154.
e $155^{\circ}$ (2012: $722-723$ ).

11 Traduzido como "Don't be touching me", a expressão exprime a proibição do toque, sendo a sua genealogia remetida para a mundividência cristã: é atribuída a Jesus Cristo, que a terá proferido perante Maria Madalena (Nancy, 2008). 


\section{A CARTOGRAFiA JURÍdicA DA} CORPORALIDADE E O ACOLHIMENTO DO 'IMPERATIVO COITAL'

A ideia, latente na proibição do toque ('noli me tangere'), do corpo como reduto da sexualidade, verte-se também em diferentes investimentos simbólicos do corpo e da identidade sexual dos sujeitos. O corpo é juridicamente sexualizado (e hierarquizado), investido ele próprio de diferentes significações que subjazem à valoração escalonada dos diferentes tipos de atos sexuais. Emerge, assim, o que poderemos designar como cartografia jurídica da corporalidade, ou, como afirma Richard MacKinnon, uma codificação social [e jurídica] da anatomia, onde determinadas partes do corpo recebem conotações valorativas diferenciadas (1997: 19). Assim, escreve o autor, "assaults involving penis/anus/vagina are socially constructed differently from those

\footnotetext{
12 A primeira formulação do termo, proposta por Margaret Jackson em 1984, incidia sobre o acervo científico em torno da sexualidade, que a autora denunciava como normalizador de uma determinada visão da sexualidade e das relações entre géneros.
}

involving finder/ear/nose" (1997: 19), asserção que parece confirmada pela já referida supremacia valorativa da penetração. Esta sexualidade fisiológico externa, na expressão tomada de Figueiredo Dias, parece, ultimamente, genitalizada (Potts, 2002; Seidman, 2003), assim como a identidade sexual dos sujeitos (vejam-se as referências na doutrina sobre "o membro viril" e a "vagina da mulher"): os genitais parecem investidos da centralidade da dimensão sexual.

A periferização das manifestações não genitalizadas da sexualidade, testemunhadas por qualificações sociais dominantes como "preliminares", ou, no contexto em causa, por tipificações jurídicas como contacto de natureza sexual e ato sexual de relevo, mas sem a relevância do ato penetrativo, parece ir ao encontro do designado 'imperativo coital'.11 $11^{12}$ : processo descrito como a dominante equivalência assumida entre relação sexual e penetração vaginal

12 O então Presidente dos Estados Unidos da América afiançava não ter existido relação sexual entre si e a estagiária da Casa Branca, argumentando depois que tal não tinha ocorrido verdadeiramente, uma vez que não se tinha verificado penetração vaginal. 
(Jackson, 1984; McPhillips et al., 2001). Como ilustração da dominante permutabilidade, assumida entre aquela penetração e relação sexual, Nicola Gavey refere o caso ultra-mediatizado de Bill Clinton, aquando da negação do envolvimento sexual com Monica Lewinsky.12 ${ }^{12}$, considerando que a alegação do então Presidente dos Estados Unidos da América revela mais do que pura idiossincrasia (2005: 9). No contexto penal português, a interação sexual parece derradeiramente efetivada pela dimensão de 'introdução', na expressão de Mouraz Lopes, no corpo de outrem.

A centralidade valorativa da cópula, estendida à atual centralidade punitiva da penetração com partes do corpo ou objetos, parece ainda repousar numa visão essencialista da sexualidade, de feição biologista, que compreende a sexualidade como fenómeno pré-social e que desconsidera o que se apresente como desvio ao figurino tradicional do sexo genital (Abbott et al., 2005). Quando a construção jurídica da violação era ainda permutável com cópula não consentida com mulher, escrevia Teresa Pizarro Beleza: "Poder-se-ia dizer, por exemplo: a definição legal da violação é falocêntrica", acrescentando que "a essência da sexualidade, do 'acto sexual', é vista como a penetração da vagina pelo pénis - visão hoje amplamente desmentida como centro do prazer feminino, nas teorizações pósfreudianas" (1990: 335) Ulteriormente, e já no contexto jurídico contemporâneo onde a violação legal encontra outra latitude de atos penetrativos, como supra explanado - o fundo simbólico falocêntrico é ainda argumentável. Referindo-se à primazia e omnipresença discursiva do "pénis ereto" nos acórdãos, um/a dos entrevistados/as na pesquisa de Isabel Ventura resume o imaginário jurídico vigente em matéria de criminalidade sexual como "sociedade falocêntrica da penetração" (Ventura, 2016b: 47).

Se é certo que tal conceção essencialista e androcêntrica, antes plenamente consagrada, surge agora mitigada pela mutação do conceito legal de violação (pela inclusão de outros atos penetrativos que não o vaginal e pela introdução de objetos), parecem detetar-se ainda fortes resquícios desta visão normativa da sexualidade - tais como a 
persistência da primazia da penetração e a delegação no critério médico quanto à determinação do conceito de cópula.

\section{NOTAS CONCLUSIVAS}

A compreensão da sexualidade como fenómeno socialmente construído e contingente (Seidman, 2003; Tiefer, 1995) permite ler as mutações legais na criminalidade sexual, suas disrupções e continuidades, como expressões de um processo mais amplo de contínua reconfiguração dos referentes relativos à atividade sexual. A construção jurídica da interação sexual não se limita a absorver, receber e mimetizar as construções sociais dominantes: a determinação dos conceitos e categorias jurídicas, sobretudo no âmbito criminal, é também produtora de sentido (Beleza, 1996: 176).

A delimitação jurídica do âmbito sexual com relevância penal, assente numa visão tradicionalista e fisicalista da sexualidade, terá negligenciado dimensões da vivência e autodeterminação sexual dos sujeitos. Neste contexto, a propósito do assédio laboral e de rua, Clara Sottomayor afirma que:

\begin{abstract}
a sexualidade não é apenas um fenómeno físico, [pelo que] também a ofensa à liberdade sexual não envolve necessariamente contatos físicos. A palavra também pode consistir numa forma de praticar um crime, que ofende a liberdade, a integridade psicológica e a autodeterminação sexual de uma pessoa $(2015,119)$.
\end{abstract}

O reconhecimento da ampla esfera da sexualidade, inesgotável na dimensão do contacto físico, parece tão mais essencial quanto os novos desafios e mutações na intimidade desafiam o tradicional entendimento da relação sexual como encontro dos corpos. Da crescente mediação tecnológica e das novas formas de comunicação emergem novas formas de interação sexual, que impõem questionamentos e desafiam o entendimento da sexualidade como relação física entre os sujeitos. Corolário desta realidade, a cibersexualidade e as novas dinâmicas relacionais que a acompanham introduzem problemas ontológicos (Collins, 2008), sociológicos e jurídicos - sendo que se afigura possível que, no futuro, demonstrem os limites da conceção fisicalista na proteção e tutela da liberdade sexual.

\section{ABREVIATURAS:}




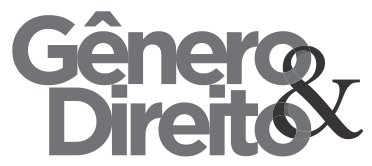

CP: Código Penal

\section{REFERÊNCIAS BIBLIOGRÁFICAS:}

Abbott, Pamela; Melissa Tyler; Claire

Wallace. An introduction to sociology:

Feminist perspectives. Routledge, 2006.

Albuquerque, Paulo Pinto de (2009), “A

Coacção Sexual e a Violação no Código

Penal Português", in Liber Amicorum de

José de Sousa e Brito, Coimbra: Edições Almedina.

Albuquerque, Paulo Pinto de (2015), Comentário do Código Penal à luz da Constituição da República e da Convenção Europeia dos Direitos do Homem. Lisboa: Editora Universidade Católica. [ $3^{\mathrm{a}}$ ed.]

Beleza, Teresa Pizarro (1990) Mulheres, Direito, Crime ou A Perplexidade de Cassandra. Lisboa, AAFDL.

Beleza, Teresa Pizarro (1994). "O conceito legal de violação", separata da Revista do Ministério Público, 59, 51-64.
Beleza, Teresa Pizarro (1996), "Sem sombra de pecado. O repensar dos Crimes Sexuais na Revisão do Código Penal", Jornadas de Direito Criminal, Revisão do Código Penal, Vol. I. Lisboa: CEJ.

Collins, Louise. "Is Cybersex Sex?." The Philosophy of Sex: Contemporary Readings (2008): 115-131.

Dias, Jorge de Figueiredo, Caeiro, Pedro (1997), "Crimes contra a liberdade e autodeterminação sexual", Polis. Enciclopédia Verbo da Sociedade e do Estado, 1394-1403. Lisboa: Verbo.

Dias, Jorge de Figueiredo (2012) [dir.], Comentário conimbricense do Código Penal. Parte Especial. tomo I: art. $131 .^{\circ}$ a 201..$^{\circ}\left[2 .^{\mathrm{a}} \mathrm{ed}\right.$.], Coimbra: Coimbra Editora, p. $550-900$ [2 $2^{\mathrm{a}}$ ed. $]$

Gavey, Nicola (2005), Just Sex? The Cultural Scaffolding of Rape. New York: Routledge.

Gonçalves, Manuel Lopes Maia (2007), Código Penal Português: Anotado e 
comentado. Legislação complementar. Coimbra: Livraria Almedina. [18 ed.]

Jackson, Margaret (1984) "Sex research and the construction of sexuality: a tool of male supremacy?", Women's Studies International Forum, vol. 7, n. ${ }^{\circ} .1,43-51$.

Leite, Inês Ferreira (2011), “A Tutela Penal da Liberdade Sexual", Revista Portuguesa de Ciência Criminal. Ano 21, n. ${ }^{\circ}$ 1. Janeiro-Março. Coimbra: Coimbra Editora.

Lopes, José Mouraz (2008), Os crimes contra a liberdade e autodeterminação sexual no Código Penal, Coimbra: Coimbra Editora [4. ${ }^{\mathrm{a}}$ ed].

Lopes, José Mouraz; Milheiro, Tiago Caiado (2016). Crimes Sexuais - Análise Substantiva e Processual. Coimbra: Coimbra Editora.

Mackinnon, Richard (1997), "Virtual Rape", in Journal of Computer-Mediated Communication, Vol. 2(4), 1-20.
McPhillips, Katherine; Braun, Virginia; Gavey, Nicola (2001), "Defining (Hetero)Sex: How Imperative is the 'Coital Imperative'?", in Women's Studies International Forum, Vol. 24, n. ${ }^{\circ}$. 2, 229-240.

Nancy, Jean Luc (2008). Noli Me Tangere: On the Raising of the Body. Trad. Sarah Clift, Pascale-Anne Brault e Michael NaasFordham University Press. Potts, Annie (2002). The sciencelfiction of sex: Feminist deconstruction and the vocabularies of heterosex. Psychology Press.

Rodrigues, Anabela Miranda; Fidalgo, Sónia (2012), «Importunação sexual», in Comentário Conimbricense do Código Penal. Parte Especial, tomo I: art. ${ }^{\circ} 131,^{\circ}$ a 201.', Coimbra: Coimbra Editora, 816831 [2 $2^{\mathrm{a}}$ ed.]

Silva Dias, Maria do Carmo (2008), "Repercussões da Lei no 59/2007, de 4/9 nos 'crimes contra a liberdade sexual'", in Revista do Centro de Estudos Judiciários: n. ${ }^{\circ} 8,213-279$. 
Silva Dias, Maria do Carmo (2000), “A propósito do crime de violação: ainda faz sentido a sua autonomização?", in Revista do Ministério Público, n. 21 - JaneiroMarço, 57-90.

Seidman, Steven (2003). The social construction of sexuality. New York: Norton.

Sottomayor, Maria Clara (2011). "O conceito legal de violação: um contributo para a doutrina penalista. A propósito do acórdão do Tribunal da Relação do Porto, de 13 de Abril de 2011", Revista do Ministério Público, 128, OutubroDezembro, 273-318.

Sottomayor, Maria Clara (2015). A Convenção de Istambul e o novo paradigma da violência de género. Ex aequo, (31), 105-121.

Tiefer, Leonore (1995). Sex is not a natural act and other essays. Westview Press.

Ventura, Isabel (2013). "O crime de violação: Subsídios para uma história penal", Mulheres: Feminino, Plural. Funchal: Nova Delphi.

Ventura, Isabel (2016a) Medusa no Palácio da Justiça: imagens sobre mulheres, sexualidade e violência a partir dos discursos e práticas judiciais. Universidade do Minho. [Dissertação de Doutoramento]

Ventura, Isabel (2016b) “A violação na jurisprudência e na doutrina", Combate à Violência de Género: Da Convenção de Istambul à nova legislação penal, 39-68. Porto: Universidade Católica Editora.

\section{JURISPRUDÊNCIA}

Acórdão do Supremo Tribunal de Justiça n. ${ }^{\circ}$ 5/2003. Publicado no Diário $d a$ República, I série - A, de 17/10/03. 